\title{
Solusi Numerik Persamaan Gelombang Dua Dimensi Dengan Metode Beda Hingga Skema Eksplisit CTCS
}

\author{
Allifia Nur Chasanah1, Mohammad Jamhuri², Evawati Alisah² \\ ${ }^{1}$ Mahasiswa Jurusan Matematika, Fakultas Sains dan Teknologi UIN Maulana Malik Ibrahim, \\ Malang \\ ${ }_{2}^{2}$ Jurusan Matematika, Fakultas Sains dan Teknologi UIN Maulana Malik Ibrahim Malang \\ Email: lifia.achanur@ymail.com,m.jamhuri@live.com, evawatialisah@uin-malang.ac.id
}

\begin{abstract}
ABSTRAK
Dalam tulisan ini dibahas tentang penyelesaian persamaan gelombang linier dua dimensi menggunakan metode beda hingga. Persamaan beda diperoleh dengan cara melakukan diskritisasi terhadap persamaan differensial parsial yang menyatakan pergerakan gelombang menggunakan skema eksplisit centered time centered space. Untuk menjamin kekonvergenan solusi yang diperoleh dari penyelesaian numerik ini digunakan analisis kestabilan Von Neumann dan analisis konsistensi terhadap persamaan beda hasil diskritisasi. Untuk mensimulasikan kestabilan solusi diberikan dua contoh yang menyatakan stabil atau tidaknya solusi yang diperoleh.
\end{abstract}

Kata Kunci: Persamaan gelomang dua dimensi, metode beda hingga, skema eksplisit CTCS, syarat kestabilan, syarat konsistensi.

\begin{abstract}
This paper discusses the solution to the two-dimensional linear wave equation using the finite difference method. The different equations are obtained by discretizing the partial differential equations that express the wave motion using an explicit centered time centered space scheme. To ensure the convergence of the solution obtained from this numerical solution, the Von Neumann stability analysis and the consistency analysis of the discretized differential equations are used. To simulate the stability of the solution, two examples are given which state whether the solution is stable or not.
\end{abstract}

Keywords: Two-dimensional wave equation, finite difference method, CTCS explicit scheme, stability requirements, consistency requirements.

\section{PENDAHULUAN}

Persamaan gelombang dua dimensi dapat digunakan untuk mensimulasikan pergerakan gelombang air dalam sebuah kanal yang berbentuk persegi panjang. Kondisi gelombang air pada suatu waktu dapat dinyatakan dalam bentuk fungsi dua variabel yang menyatakan ketinggian permukaan air pada koordinat yang diwakili oleh kedua variabel dalam fungsi tersebut. Kecapatan awal penyebaran gelombang air dapat dinyatakan sebagai turunan dari fungsi yang menyatakan keadaan awal gelombang air terhadap waktu. 
Jika area penyebaran gelombang merupakan daerah yang tertutup seperti kolam dimana air tidak akan keluar dari area penyebaran atau media, maka kondisi ini dapat dinyatakan sebagai sebuah kondisi pada batas yang dinamakan kondisi batas Neumann, yaitu suatu persamaan diferensial yang menyatakan kondisi tidak ada pergerakan air yang kelual dan masuk melewati batas-batas [1], [2].

Jika pergerakan gelombang air dikondisikan memiliki ketinggian yang tidak berubah seiring adanya perubahan waktu, maka kondisi semacam itu dapat dinyatakan sebagai sebuah kondisi yang dinamakan sebagai kondisi batas Dirichlet [3]. Tetapi jika kondisi pergerakan air pada sisi-sisi kanal tidak seragam, maka kondisi pada batas dapat dinyatakan menggunakan perpaduan dari kondisi Neumann maupun Dirichlet [4], [5], [6], [7].

Persamaan gelombang yang akan digunakan untuk mensimulasikan pergerakan gelombang air dalam tulisan ini adalah persamaan gelombang linier dimensi dua yang dapat diturunkan menggunakan [8], [9]. Persamaan gelombang merupakan persamaan parsial hiperbolik linear order kedua yang menggambarkan propagasi gelombang, diantaranya gelombang suara dan gelombang air.

Terdapat dua metode dalam menyelesaikan persamaan gelombang, yaitu penyelesaian secara analitik dan penyelesaian secara numerik. Karena metode analitik tidak selalu memberikan hasil, maka metode numerik merupakan metode yang paling banyak diandalkan didalam penyelesaian masalah-masalah persamaan differensial. Beberapa metode numerik atau hampiran dalam penyelesaian persamaan gelombang dalam [10] yaitu metode volume hingga, metode beda hingga, metode elemen hingga, metode spektral, neural network [11], dan lain sebagainya [12]. Metode-metode hampiran tersebut cenderung tidak stabil secara komputasi, sehingga diperlukan analisis untuk mencegah hal tersebut, yaitu salah satunya dengan menentukan syarat kestabilan menggunakan metode Von Neumann [13].

\section{METODE}

\section{Diskritisasi}

Pada tulisan ini persamaan diferensial beserta kondisi awal dan kondisi batas pada persamaan (1)-(4) diselesaikan menggunakan metode hampiran numerik skema CTCS. Persamaan (1) didiskrtikan menjadi

$$
\frac{u_{i, j}^{n+1}-2 u_{i, j}^{n}+u_{i, j}^{n-1}}{\Delta t^{2}}=c^{2}\left(\frac{u_{i+1, j}^{n}-2 u_{i, j}^{n}+u_{i-1, j}^{n}}{\Delta x^{2}}+\frac{u_{i, j+1}^{n}-2 u_{i, j}^{n}+u_{i, j-1}^{n}}{\Delta y^{2}}\right)
$$

dengan $i=2, \ldots,(M-1), j=2, \ldots,(N-1)$, dan $t=2, \ldots$. Persamaan diatas dapat dituliskan menjadi

$$
u_{i, j}^{n+1}=\frac{c^{2} \Delta t^{2}}{\Delta x^{2}}\left(u_{i+1, j}^{n}-2 u_{i, j}^{n}+u_{i-1, j}^{n}\right)+\frac{c^{2} \Delta t^{2}}{\Delta y^{2}}\left(u_{i, j+1}^{n}-2 u_{i, j}^{n}+u_{i, j-1}^{n}\right)+2 u_{i, j}^{n}-u_{i, j}^{n-1}
$$

Tanpa mengurangi perumuman, akan dipilih $\Delta x=\Delta y$ sedemikian hingga persamaan diatas dapat disederhanakan menjadi

$$
u_{i, j}^{n+1}=s\left(u_{i+1, j}^{n}+u_{i-1, j}^{n}+u_{i, j+1}^{n}+u_{i, j-1}^{n}\right)+(2-4 s) u_{i, j}^{n}-u_{i, j}^{n-1}
$$


dengan $s=c^{2} \Delta t^{2} / \Delta x^{2}$.

Kondisi awal pada persamaan (2) didiskritkan menjadi $u_{i, j}^{0}=\phi_{i, j}$ dan

$$
\frac{u_{i, j}^{2}-u_{i, j}^{0}}{2 \Delta t}=0, \quad \text { atau } \quad u_{i, j}^{0}=u_{i, j}^{2}
$$

Kondisi batas pada persamaan (3) dapat dituliskan menjadi

$$
\frac{u_{2, j}^{n}-u_{0, j}^{n}}{2 \Delta x}, \quad \text { dan } \quad \frac{u_{M+1, j}^{n}-u_{M-1, j}^{n}}{2 \Delta x}=0
$$

Persamaan-persamaan diatas dapat ditulis menjadi

$$
u_{0, j}^{n}=u_{2, j}^{n}, \quad \text { dan } \quad u_{M+1, j}^{n}=u_{M-1, j}^{n}
$$

Berikutnya kondisi batas pada persamaan (4) dapat didiskritkan menjadi

$$
\frac{u_{i, 2}^{n}-u_{i, 0}^{n}}{2 \Delta y}=0, \quad \text { dan } \quad \frac{u_{i, N+1}^{n}-u_{i, N-1}^{n}}{2 \Delta y}=0
$$

Persamaan-persamaan diatas dapat dituliskan sebagai

$$
u_{i, 0}^{n}=u_{i, 2}^{n}, \quad \text { dan } \quad u_{i, N+1}^{n}=u_{i, N-1}^{n}
$$

\section{Kestabilan}

Analisis kestabilan dilakukan untuk menentukan batas nilai $s$ pada persamaan beda (5) diatas agar solusi yang diperoleh konvergen. Untuk menentukan nilai $s$ akan digunakan metode kestabilan Von Neumann, yaitu dengan memisalkan $u_{i, j}^{n}=\rho^{n} e^{I a(i+j)}$ dengan $I=\sqrt{-1}, a \in \mathbb{R}$ dan mensubstitusikan pada persamaan beda (5), selanjutnya diperoleh :

$$
\rho^{n+1} e^{I a(i+j)}=2 s \rho^{n}\left(e^{I a(i+j+1)}+e^{I a(i+j-1)}\right)+(2-4 s) \rho^{n} e^{I a(i+j)}-\rho^{n-1} e^{I a(i+j)}
$$

Jika kedua ruas dari persamaan diatas dibagi dengan $\rho^{n} e^{I a(i+j)}$ diperoleh

$$
\rho=2 s\left(e^{I a}+e^{-I a}\right)+(2-4 s)-\rho^{-1},
$$

dengan mengalikan persamaan diatas dengan $\rho$ dan meletakkan semua suku di sisi kiri tanda sama dengan diperoleh

$$
\rho^{2}-\rho\left(2 s\left[e^{I a}+e^{-I a}\right]+(2-4 s)\right)+1=0
$$

Karena $e^{ \pm I a}=\cos (a) \pm I \sin (a)$ maka persamaan diatas ditulis menjadi

$$
\rho^{2}-(2 s[2 \cos a]+(2-4 s)) \rho+1=0
$$

atau

$$
\rho^{2}-(4 s(\cos a-1)+2) \rho+1=0
$$

Selanjutnya dapat digunakan rumus $a b c$ untuk menentukan nilai $\rho$ dari persamaan kuadrat diatas, yaitu 


$$
\rho_{1,2}=-\frac{b}{2} \pm \frac{1}{2} \sqrt{b^{2}-4 a c}
$$

Misalkan $a=1, b=-2(2 \mathrm{~s}(\cos a-1)+1), c=1$, dan dengan mensubstitusikan variabel $a, b$, dan $c$ pada persamaan (9) diatas, diperoleh

$$
\rho_{1,2}=[2 s(\cos a-1)+1] \pm \sqrt{[2 s(\cos a-1)+1]^{2}-1}
$$

Persamaan beda (5) akan stabil jika nilai $\rho$ pada persamaan jika nilai norm-nya kurang dari satu. Penjelasan lebih lengkap dapat dilihat pada [14], dan persamaan beda diatas stabil jika memenuhi

$$
s \leq \frac{1}{2}
$$

\section{Konsistensi Persamaan Beda}

Persamaan beda konsisten jika persamaan tersebut dapat dideretkan menggunakan persamaan Taylor dan limit dari persamaan tersebut sama dengan persamaan differensial semula.

Berdasarkan analisis yang telah dilakukan, dapat ditunjukkan bahwa persamaan beda (5) konsisten [14] dengan orde error pemotongan $\mathcal{O}\left(\Delta x^{2}, \Delta y^{2}, \Delta t^{3}\right)$. Sebagai akibatnya jika nilai $\Delta x, \Delta y$, dan $\Delta t$ dipilih sedemikian hingga nilai $s$ memenuhi syarat kestabilan dalam persamaan (10), maka solusi yang diperoleh dari persamaan beda akan konvergen pada solusi eksak dari persamaan differensial (1) yang diselesaikan.

\section{HASIL DAN PEMBAHASAN}

Berikut ini adalah persamaan-persamaan diskrit yang diperoleh dari uraian secara aljabar persamaan beda beserta kondisi awal dan kondisi batas pada bagian sebelumnya. Selanjutnya persamaan-persamaan akan digunakan sebagai landasan dalam menuliskan kode program untuk simulasi. Pada tulisan ini, langkah-langkah untuk mendapatkan persamaan-persamaan berikut tidak dapat dicantumkan secara mendetail karena keterbatasan jumlah halaman yang diijinkan, sehingga hanya hasil akhir saja yang diberikan.

\section{Untuk $n=1$}

Untuk $n=1$ persamaan beda (5) menjadi

$$
u_{i, j}^{2}=s\left(u_{i+1, j}^{1}+u_{i-1, j}^{1}+u_{i, j+1}^{1}+u_{i, j-1}^{1}\right)+(2-4 s) u_{i, j}^{1}-u_{i, j}^{0} .
$$

Dengan menggunakan kondisi awal (6) kita punya $u_{i, j}^{0}=u_{i, j}^{2}$, setelah disubstitusikan pada persamaan diatas diperoleh

$$
u_{i, j}^{2}=\frac{s}{2}\left(u_{i+1, j}^{1}+u_{i-1, j}^{1}+u_{i, j+1}^{1}+u_{i, j-1}^{1}\right)+(1-2 s) u_{i, j}^{1} .
$$

Pada $i=1$,

- Pada $j=1$ persamaan yang digunakan adalah

$$
u_{1,1}^{2}=s\left(u_{2,1}^{1}+u_{1,2}^{1}\right)+(1-2 s) u_{1,1}^{1}
$$

- Pada $j=2, \ldots,(N-1)$ persamaan yang digunakan adalah 


$$
u_{1, j}^{2}=\frac{s}{2}\left(2 u_{2, j}^{1}+u_{1, j+1}^{1}+u_{1, j-1}^{1}\right)+(1-2 s) u_{1, j}^{1}
$$

- $\quad$ Pada $j=N$ persamaan yang digunakan adalah

$$
u_{1, N}^{2}=s\left(u_{2, N}^{1}+u_{1, N-1}^{1}\right)+(1-2 s) u_{1, N}^{1}
$$

Pada $i=2, \ldots,(M-1)$

- Pada $j=1$ persamaan yang digunakan adalah

$$
u_{i, 1}^{2}=\frac{s}{2}\left(u_{i+1,1}^{1}+u_{i-1,1}^{1}+2 u_{i, 2}^{1}\right)+(1-2 s) u_{i, 1}^{1}
$$

- Pada $j=2, \ldots,(N-1)$ persamaan yang digunakan adalah

$$
u_{i, j}^{2}=\frac{s}{2}\left(u_{i+1, j}^{1}+u_{i-1, j}^{1}+u_{i, j+1}^{1}+u_{i, j-1}^{1}\right)+(1-2 s) u_{i, j}^{1}
$$

- $\quad$ Pada $j=N$ persamaan yang digunakan adalah

$$
u_{i, N}^{2}=\frac{s}{2}\left(u_{i+1, N}^{1}+u_{i-1, N}^{1}+2 u_{i, N-1}^{1}\right)+(1-2 s) u_{i, N}^{1}
$$

Pada $i=M$

- Pada $j=1$ persamaan yang digunakan

$$
u_{M, 1}^{2}=s\left(u_{M-1,1}^{1}+u_{M, 2}^{1}\right)+(1-2 s) u_{M, 1}^{1}
$$

- Pada $j=2, \ldots,(N-1)$ persamaan yang digunakan adalah

$$
u_{M, j}^{2}=\frac{s}{2}\left(2 u_{M-1, j}^{1}+u_{M, j+1}^{1}+u_{M, j-1}^{1}\right)+(1-2 s) u_{M, j}^{1}
$$

- Pada $j=N$ persamaan yang digunakan adalah

$$
u_{M, N}^{2}=s\left(u_{M-1, N}^{1}+u_{M, N-1}^{1}\right)+(1-2 s) u_{M, N}^{1}
$$

\section{Untuk $n>1$,}

Pada $i=1$

- Pada $j=1$ persamaan yang digunakan

$$
u_{1,1}^{n+1}=2 s\left(u_{2,1}^{n}+u_{1,2}^{n}\right)+(2-4 s) u_{1,1}^{n}-u_{1,1}^{n-1}
$$

- Pada $j=2, \ldots,(N-1)$ persamaan yang digunakan adalah

$$
u_{1, j}^{n+1}=s\left(2 u_{2, j}^{n}+u_{1, j+1}^{n}+u_{1, j-1}^{n}\right)+(2-4 s) u_{1, j}^{n}-u_{1, j}^{n-1}
$$

- Pada $j=N$ persamaan yang digunakan adalah

$$
u_{1, N}^{n+1}=2 s\left(u_{2, N}^{n}+u_{1, N-1}^{n}\right)+(2-4 s) u_{1, N}^{n}-u_{1, N}^{n-1}
$$

Pada $i=2, \ldots,(M-1)$

- Pada $j=1$ persamaan yang digunakan adalah

$$
u_{i, 1}^{n+1}=s\left(u_{i+1,1}^{n}+u_{i-1,1}^{n}+2 u_{i, 2}^{n}\right)+(2-4 s) u_{i, 1}^{n}-u_{i, 1}^{n-1}
$$

- Pada $j=2, \ldots,(N-1)$ persamaan yang digunakan adalah

$$
u_{i, j}^{n+1}=s\left(u_{i+1, j}^{n}+u_{i-1, j}^{n}+u_{i, j+1}^{n}+u_{i, j-1}^{n}\right)+(2-4 s) u_{i, j}^{n}-u_{i, j}^{n-1}
$$


- $\quad$ Pada $j=N$ persamaan yang digunakan adalah

$$
u_{i, N}^{n+1}=s\left(u_{i+1, N}^{n}+u_{i-1, N}^{n}+2 u_{i, N-1}^{n}\right)+(2-4 s) u_{i, N}^{n}-u_{i, N}^{n-1}
$$

Pada $i=M$

- Pada $j=1$ persamaan yang digunakan adalah

$$
u_{M, 1}^{n+1}=2 s\left(u_{M-1,1}^{n}+u_{M, 2}^{n}\right)+(2-4 s) u_{M, 1}^{n}-u_{M, 1}^{n-1}
$$

- Pada $j=2, \ldots,(N-1)$ persamaan yang digunakan adalah

$$
u_{M, j}^{n+1}=s\left(2 u_{M-1, j}^{n}+u_{M, j+1}^{n}+u_{M, j-1}^{n}\right)+(2-4 s) u_{M, j}^{n}-u_{M, j}^{n-1}
$$

- Pada $j=N$ persamaan yang digunakan adalah

$$
u_{M, N}^{n+1}=2 s\left(u_{M-1, N}^{n}+u_{M, N-1}^{n}\right)+(2-4 s) u_{M, N}^{n}-u_{M, N}^{n-1}
$$

\section{Simulasi 1}

Berikut ini adalah hasil simulasi program yang diperoleh menggunakan nilai $l=$ $m=5$, kemudian $\Delta x=\Delta y=0.1$ dan $\Delta t=0.05$ serta $T=10$, sedangkan $\Phi(x, y)=$ $\operatorname{sech}^{2}\left(x^{2}+y^{2}\right)$. Hasil simulasi untuk beberapa $t$ dapat dilihat pada gambar berikut:
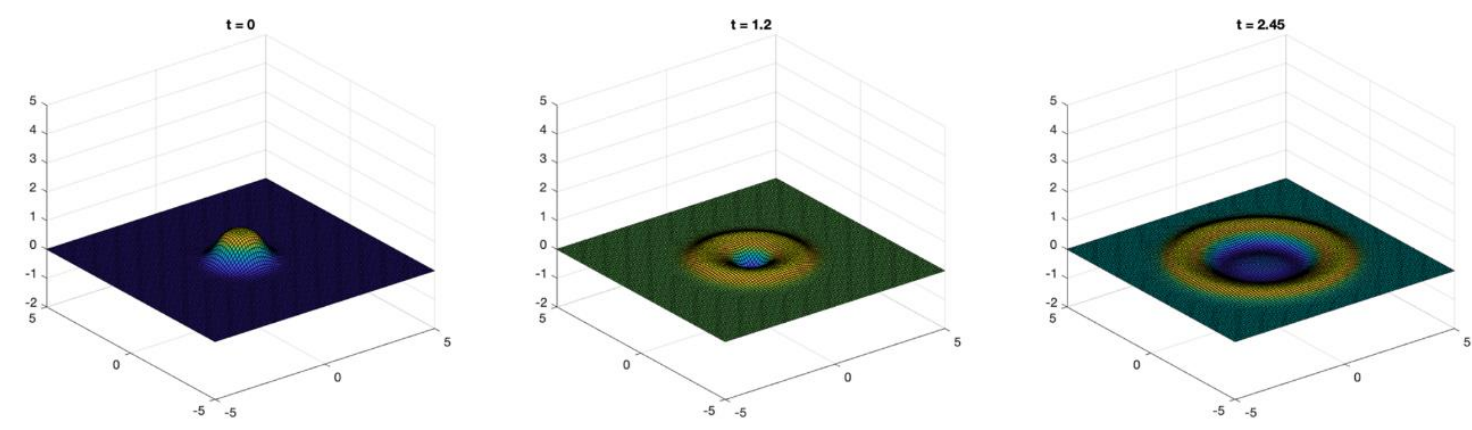

Gambar 1. Hasil simulasi untuk $\mathrm{t}=0, \mathrm{t}=1.2$, dan $\mathrm{t}=2.45$
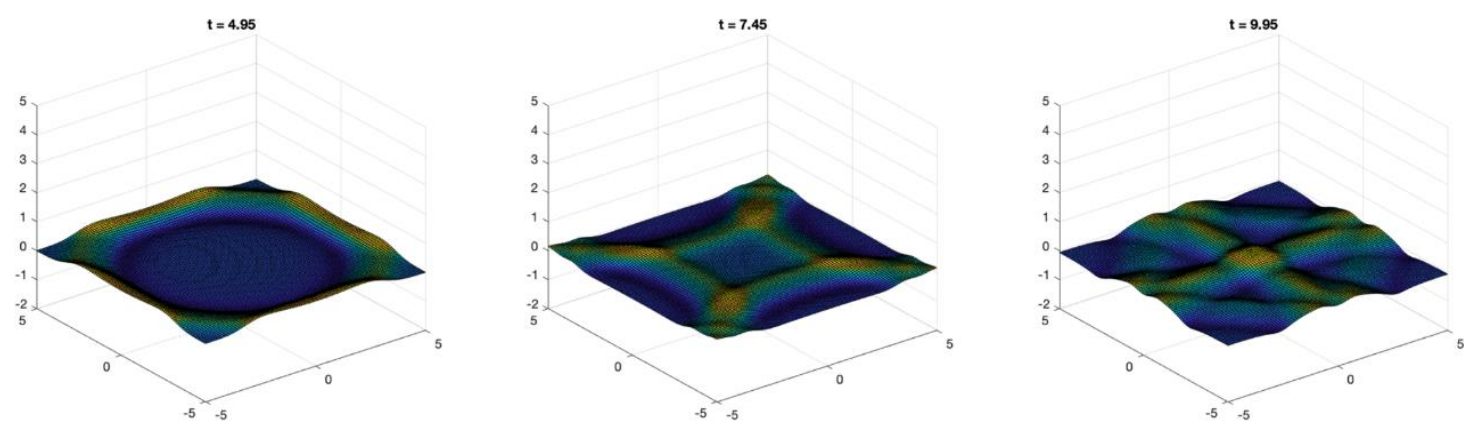

Gambar 2. Hasil simulasi untuk $\mathrm{t}=4.95, \mathrm{t}=7.45$, dan $\mathrm{t}=9.95$

\section{Simulasi 2}

Berikut ini adalah hasil simulasi program yang diperoleh menggunakan nilai $l=$ $m=5$, kemudian $\Delta x=\Delta y=0.1$ dan $\Delta t=0.075$ serta $T=10$, sedangkan $\Phi(x, y)=$ $\operatorname{sech}^{2}\left(x^{2}+y^{2}\right)$. Hasil simulasi untuk beberapa $t$ dapat dilihat pada gambar berikut: 

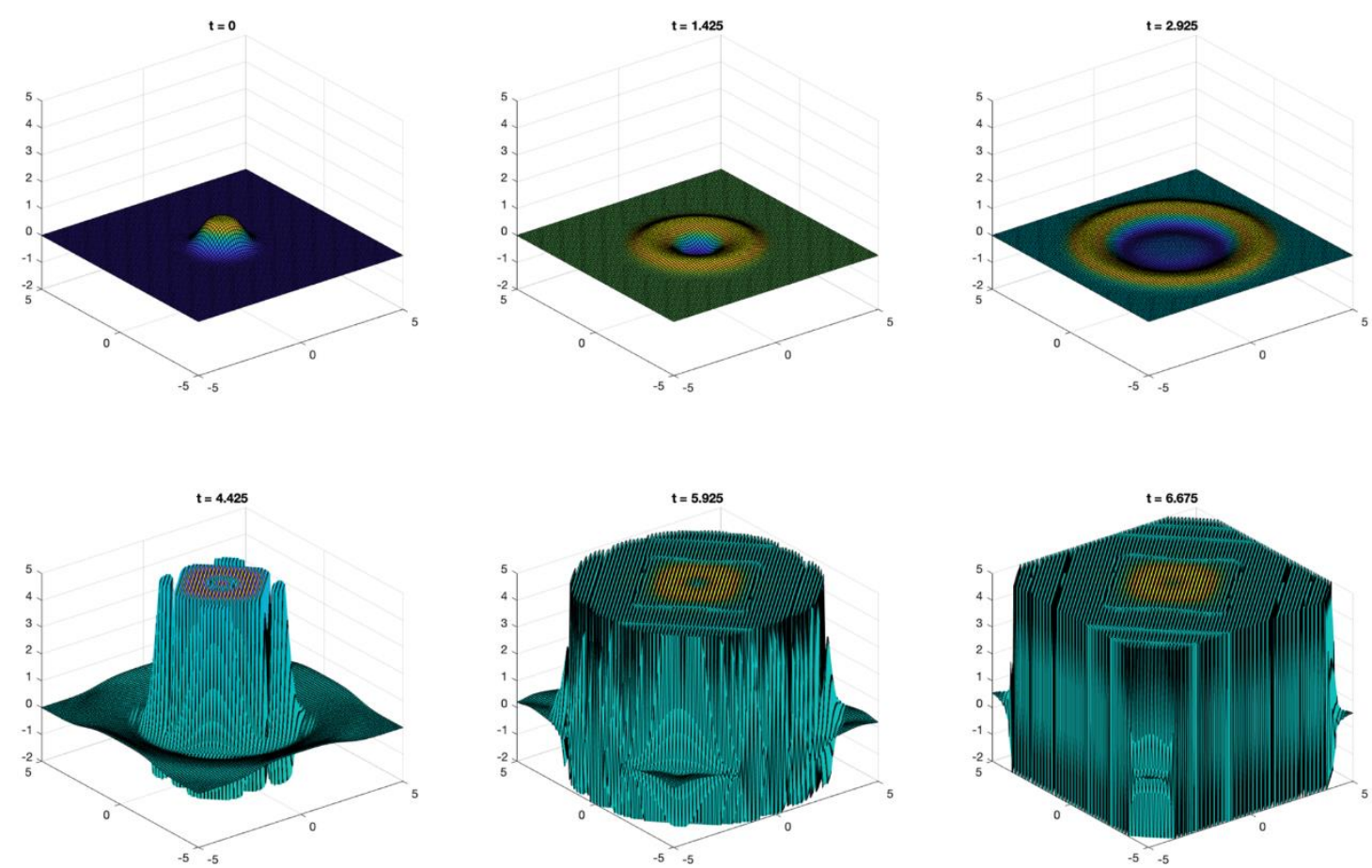

Figure 3. Hasil simulasi dengan nilai $s>0.5$

Kode program Matlab untuk menghasilkan simulasi 1 dan simulasi pada Gambar 13 diatas dapat diperoleh di matworks.com/fileexchange [15].

Pada simulasi 1 , dipilih nilai $\Delta x, \Delta y, \Delta t$ sedemikian hingga dapat memenuhi syarat kestabilan yaitu nilai $s$ kurang dari $\frac{1}{2}$. Dapat dilihat hasil simulasi pada Gambar 1 dan Gambar 2 bahwa nilai-nilai solusi yang diperoleh yang dinyatakan kedalam kurva ketinggian atau surf terbatas pada suatu rentang tertentu. Pada simulasi 1 digunakan $t \in$ $[0,21]$ dan dapat dilihat bahwa nilai-nilai solusi yang diperoleh tidak terjadi blow up, meskipun nilai $t$ dibuat menjadi lebih besar (pembaca dapat mencoba mengubah nilai $T$ pada kode program yang link-nya telah dicantumkan diatas).

Pada simulasi 2, dipilih nilai-nilai $\Delta x, \Delta y, \Delta t$ yang menyebabkan nilai $s>\frac{1}{2}$ atau tepatnya $s=0.5625$, yang berarti tidak memenuhi syarat kestabilan. Hasil yang diperoleh untuk $t$ tertentu menunjukkan bahwa solusi tidak stabil. Hal tersebut ditandai oleh semakin besarnya nilai solusi jika nilai $t$ semakin bertambah besar dan pada akhirnya nilai solusi akan menuju tak hingga.

Dapat dilihat pada Gambar 3, sebelum penyebaran gelombang sampai pada batas solusi atau ketinggian gelombang terlihat baik-baik saja, tetapi setelah gelombang yang berasal dari pusat berinteraksi dengan pantulan gelombang yang berasal dari batasbatas, solusi menjadi tidak stabil. Simulasi ini dilakukan untuk analisis uji kestabilan dan kekonvergenan yang menunjukkan bahwa grafik stabil dalam kriteria kestabilan yang ditetapkan dan konvergen. Kestabilan ini juga dapat digunakan sebagai acuan bahwa error tidak berkembang saat diterapkan kriteria kestabilan.

Berikut ini adalah hasil simulasi program untuk $t=107$ dan dipilih nilai-nilai $\Delta x, \Delta y, \Delta t$ sedemikian hingga $s$ kurang dari $1 / 2$ dan dapat memenuhi syarat kestabilan. Dapat dilihat bahwa untuk $t$ yang cukup besar solusi tidak mengalami blow-up, tetapi jika di hitung volumenya berdasarkan ketinggian permukaan gelombang pada setiap titik, semakin bertambah nilai $t$ maka nilai volumenya semakin berkurang. Hal ini disebabkan 
oleh adanya error yang diakibatkan oleh pemotongan orde pada hampiran persamaan dengan deret Taylor didalam melakukan diskritisasi, yang mana orde errornya adalah $\mathcal{O}\left(\Delta x^{3}, \Delta t^{3}, \Delta t^{3}\right)$.

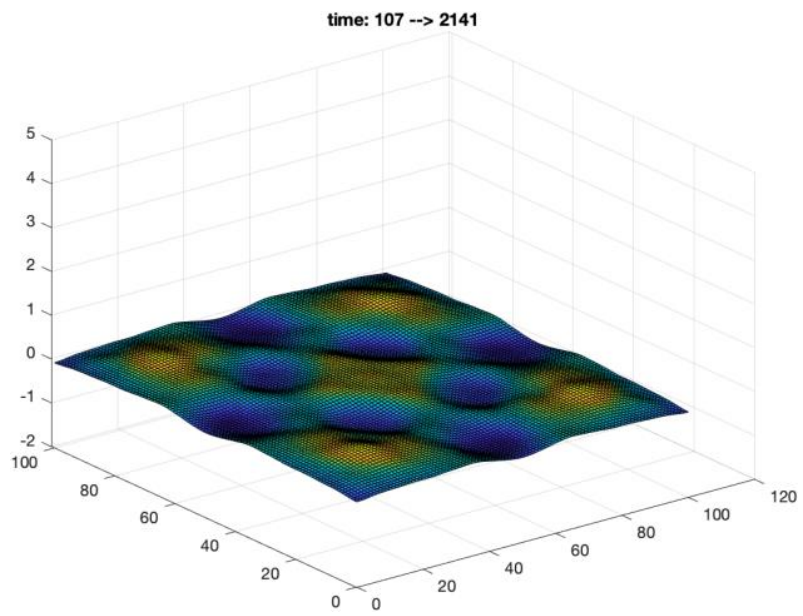

Figure 4. Simulasi solusi untuk $\mathrm{s}<0.5$ pada $\mathrm{t}=107$

\section{KESIMPULAN}

Berdasarkan pembahasan, dapat diperoleh bebereapa kesimpulan sebagai berikut, diantaranya skema numerik eksplisit CTCS untuk persamaan gelombang dua dimensi adalah sebagaimana yang terdapat pada persamaan (5) yaitu

$$
u_{i, j}^{n+1}=s\left(u_{i+1, j}^{n}+u_{i-1, j}^{n}+u_{i, j+1}^{n}+u_{i, j-1}^{n}\right)+(2-4 s) u_{i, j}^{n}-u_{i, j}^{n-1} .
$$

Metode beda hingga skema eksplisit CTCS pada persamaan gelombang dua dimensi bersifat stabil dengan syarat kestabilan $\frac{c^{2} \Delta t^{2}}{\Delta x^{2}}+\frac{c^{2} \Delta t^{2}}{\Delta y^{2}} \leq 1$ atau $\frac{c^{2} \Delta t^{2}}{\Delta x^{2}} \leq 1 / 2$ jika dipilih nilai $\Delta x=\Delta y$.

Metode beda hingga skema eksplisit CTCS pada persamaan gelombang dua dimensi konsisten dengan orde $\operatorname{error} \mathcal{O}\left(\Delta t^{3}, \Delta x^{3}, \Delta y^{3}\right)$ dan konvergen jika mendekati nol.

\section{DAFTAR RUJUKAN}

[1] A. Lasota, "A discrete boundary value problem," in Annales Polonici Mathematici, 1968, vol. 20, no. 2, pp. 183-190.

[2] Y. Tan, C. Huang, B. Sun, and T. Wang, "Dynamics of a class of delayed reactiondiffusion systems with Neumann boundary condition," J. Math. Anal. Appl., vol. 458, no. 2, pp. 1115-1130, 2018.

[3] Y. Bazilevs, C. Michler, V. M. Calo, and T. J. R. Hughes, "Weak Dirichlet boundary conditions for wall-bounded turbulent flows," Comput. Methods Appl. Mech. Eng., vol. 196, no. 49-52, pp. 4853-4862, 2007.

[4] A. Ern and J. L. Guermond, "Linear Stabilization for First-Order PDEs," in Handbook of Numerical Analysis, 1st ed., vol. 17, Elsevier B.V., 2016, pp. 265-288.

[5] J. Droniou, "Solving convection-diffusion equations with mixed, Neumann and Fourier boundary conditions and measures as data, by a duality method," $A d v$. 
Differ. Equations, vol. 5, no. 10-12, pp. 1341-1396, 2000.

[6] M. Chai, K. Luo, H. Wang, S. Zheng, and J. Fan, "Imposing mixed DirichletNeumann-Robin boundary conditions on irregular domains in a level set/ghost fluid based finite difference framework," Comput. Fluids, vol. 214, p. 104772, 2021.

[7] A. S. Reimer and A. F. Cheviakov, "A matlab-based finite-difference solver for the poisson problem with mixed dirichlet-neumann boundary conditions," Comput. Phys. Commun., vol. 184, no. 3, pp. 783-798, 2013.

[8] T. D. Rossing and N. H. Fletcher, "Two-dimensional systems: Membranes and plates," in Principles of vibration and sound, Springer, 2004, pp. 65-94.

[9] E. Kreyszig, K. Stroud, and G. Stephenson, "Advanced engineering mathematics," Integration, vol. 9, p. 4, 2008.

[10] M. Dehghan and A. Shokri, "A numerical method for solving the hyperbolic telegraph equation," Numer. Methods Partial Differ. Equations An Int. J., vol. 24, no. 4, pp. 1080-1093, 2008.

[11] G. S. Bhatia and G. Arora, "Radial basis function methods for solving partial differential equations-a review," Indian J. Sci. Technol., vol. 9, no. 45, pp. 1-18, 2016.

[12] C. A. Duarte and J. T. Oden, A review of some meshless methods to solve partial differential equations. Texas Institute for Computational and Applied Mathematics Austin, TX, 1995.

[13] C. Udriste, V. Arsinte, and C. Cipu, "Von Neumann analysis of linearized discrete Tzitzeica PDE,” Balk. J. Geom. Appl, vol. 15, no. 2, pp. 100-112, 2010.

[14] A. N. Chasanah, "Penyelesaian Numerik Persamaan Gelombang Dua DImensi dengan Metode Beda Hingga Skema Eksplisit," 2017.

[15] M. Jamhuri, "This program consist of simulation of the two dimensional linear wave equation using finite difference method." Matlab File Exchange, 2021. 